\title{
Validation of the Anxiety Scale for Pregnancy in a Sample of Iranian Women
}

\author{
Forough Mortazavi ${ }^{*}$, Arash Akaberi ${ }^{2,3}$
}

\begin{abstract}
Objectives: Pregnancy-related anxiety is a risk factor for poor outcomes. The aim of this study was to validate the Farsi version of the Anxiety Scale for Pregnancy (ASP) in a sample of Iranian women.

Materials and Methods: After translation and back-translation of the ASP, the content validity ratio (CVR) and the content validity index (CVI) of each item were calculated based on the opinions of a panel of 10 experts. Four hundred pregnant women in the third trimester of pregnancy completed the Farsi version of the ASP. For discriminant validity, we compared the ASP mean scores of women with low and high levels of childbirth fear. Confirmatory factor analysis (CFA) was performed to investigate construct validity of the scale.

Results: No item had CVR and CVI scores less than 0.62 and 0.8 , respectively. The results of the CFA for the ASP were unsatisfactory for the proposed 5-factor model (RMSEA $=0.087$, SRMR $=0.092$, chi-square $/ d f=4.03, \mathrm{CFI}=0.87$, and $\mathrm{GFI}=0.91$ ). After removing item 9, satisfactory CFA results were obtained and the structural model fit was confirmed (RMSEA $=0.066$ (CI [0.053, 0.078]), $\mathrm{SRMR}=0.069$, chi-square $/ d f=2.71, \mathrm{CFI}=0.93, \mathrm{GFI}=0.95)$. Cronbach acoefficient for the 13 -item ASP was 0.703 . The scale showed moderate correlations with the Spielberger State-Trait Anxiety Inventory (STAI) and Childbirth Attitudes Questionnaire (CAQ) scores $(0.61,0.59$, and 0.57 , respectively) and could differentiate well between women who preferred cesarean and those requesting vaginal delivery.

Conclusion: The present study confirmed the content validity and construct validity of the Farsi version of the 13-item ASP for women in the third trimester of pregnancy.

Keywords: Anxiety, Pregnancy, Validation studies, Surveys and questionnaires
\end{abstract}

\section{Introduction}

Pregnancy is a special period in a woman's life characterized by rapid physiological, psychological, and social changes during a relatively short period that may predispose women to anxiety (1). A variety of issues in pregnancy may provoke anxiety in women. Among such issues are worries about childbirth and health of the baby, quality of care during labor, the extent of husbands' support and involvement in maternal health care, and the level of support from relatives and friends (2,3). Pregnancy anxiety is different from general anxiety. It is a relatively distinct syndrome which is provoked by pregnancy-specific fears and worries (4). Women who are anxious, experience both emotional and somatic symptoms such as worry, muscle pain, palpitation, insomnia, and gastrointestinal discomfort (2). It has been suggested that high levels of pregnancy-related anxiety play a role in preterm birth (58), postpartum depression, and caesarean (7). In addition, it could affect fetal, infant and child development $(7,9)$.

Several studies have highlighted the need for the routine measurement of pregnancy anxiety during pregnancy to enable the design of appropriate interventions (10-13).
The State-Trait Anxiety Inventory (STAI), a widely used measure of general anxiety, has also been commonly used in research on pregnancy anxiety (14). The STAI scale is suitable for assessing the general level of anxiety, but it does not measure pregnancy-specific stressors (2). Another critique of the use of STAI scale for measuring pregnancy-related anxiety is that it might not predict maternal and child outcomes $(2,15,16)$. The results of a study showed that whereas childbirth-specific anxiety was an important predictor of childbirth duration, general anxiety as measured by the STAI had no predictive value in this regard (17). It is, therefore, important to design and validate an appropriate instrument for measuring pregnancy anxiety. Since pregnancy-related anxiety involves multiple factors related to infant, mother, and childbirth, it needs to be measured by a specialized multidimensional instrument.

Apart from some instruments in a true or false format, few instruments for measuring pregnancy-related anxiety are at present available which can measure the severity of anxiety (2) and which also have a clear factorial structure. Levin examined the factorial structure of the Pregnancy 
Anxiety Scale (18). Initially, the reliability and validity of the scale were only examined using the data collected in the postpartum period and since then no further studies have been undertaken to validate this scale during the pregnancy (19). Van den Berg (1) created the Pregnancy-Related Anxiety Questionnaire (PRAQ) which was later revised by Huizink who developed the 10-item PRAQ-R scale and examined its psychometric properties. Confirmatory factor analysis (CFA) of the scale revealed the existence of three factors as follows: fear of giving birth, fear of bearing a handicapped child and concern about one's appearance (4). The scale was demonstrated to be a better predictor of childbirth outcome than general anxiety measures (17). However, it has the important limitation that it has been developed with nulliparous women in mind and in particular item 8 of the questionnaire is not relevant in the case of multiparous women.

The anxiety scale for pregnancy (ASP) has certain advantages compared to similar instruments. It covers more dimensions of pregnancy-related anxiety compared with other scales, and because it was developed and examined on both primiparous and multiparous women, it can be used for all women. The factors comprising the scale were related to the following elements: the baby, labor, marital relations, attractiveness, and support (20). In the present study, we aimed to translate and investigate the validity and reliability of the Farsi version of the ASP in a sample of Iranian pregnant women. To the best of our knowledge, no study has validated the ASP in Iranian pregnant women.

\section{Materials and Methods}

\section{Participants}

Four hundred pregnant women participated in the study. According to previous studies, there is the highest rate of anxiety in the third trimester of pregnancy, so the inclusion criteria were assigned as: being at a gestational age of greater than 27 weeks (being in the third trimester of pregnancy), having the ability to read and write in Farsi, not suffering from pregnancy complications such as preeclampsia and gestational diabetes, not having the experience of a stressful event during 6 recent months, and not suffering from clinched mental disorders.

\section{Procedures}

This cross-sectional study was conducted on pregnant women who visited 8 health clinics affiliated to Sabzevar University of Medical Sciences in Sabzevar, Iran, in 2014. Of the 16 clinics covering the urban population of Sabzevar, 8 were selected using a multi-stage sampling method. The city was divided into 4 regions, and 2 clinics were randomly selected from each region. In each clinic, we recruited all pregnant women who met the inclusion criteria. After signing the informed consent form and receiving instructions by midwives, the participants were asked to complete the Farsi version of the following 3 questionnaires: the ASP, the Spielberger STAI, and the Childbirth Attitudes Questionnaire (CAQ).

\section{Instruments}

Participants completed a questionnaire on sociodemographic and obstetric characteristics (age, level of education, employment status, family income, parity, and the desirability of pregnancy) in the third trimester of pregnancy.

\section{Anxiety Scale for Pregnancy}

Doyle-Waters developed the ASP, as a measure of anxiety that covers multidimensional components of pregnancy, based on Spielberger's theory and research on state anxiety. The ASP has 14 items, 7 positively worded and 7 negatively worded, with items responses ranging from "not at all" (1 item) to "very much" (4 items). Scores on the positively worded items were reversed to obtain the total score, which ranged from 14 to 56 , with higher scores indicating more severe anxiety. The instrument has five subscales covering the following dimensions of pregnancy anxiety which are labeled as follows: the baby (items 1 , 6, 12), labor (items 2, 5, 14), marital (items 8, 10, 11), attractive (items 3, 13), and support (items 4, 7, 9). Of 5 factors, 1 includes only positively worded items, 2 include only negatively worded items and 2 are in a mixed item format (with both negatively and positively worded items). All subscales consist of 3 items except attractive factor. Content validity and internal consistency of the ASP have been demonstrated during its initial development (Cronbach $\alpha=0.76$ ) (20).

\section{The State-Trait Anxiety Inventory}

The Spielberger STAI is a commonly used instrument which is designed to measure 2 different types of anxiety: state anxiety (A-State), a transitory emotional response to a specific situation accompanied by feeling tension and apprehension, and trait anxiety (A-Trait) which is a relatively stable disposition to perceive a wide range of situations as threatening. Accordingly, STAI consists of two 20-item scales, with each item scored on a 4-point Likert scale ranging from 1 to 4 . The total score ranges from 20 to 80 for each scale, where a higher score indicates higher anxiety (21). In an investigation of the reliability generalization of the STAI, the 2 scales demonstrated excellent internal consistency (averages $\alpha$ s >0.89) (22). These scales have been translated into Farsi. The validity and reliability of the Farsi version of the STAI, which was used in the present study, have been demonstrated by Mahram. The Cronbach a values for internal consistency of the state and trait items were 0.91 and 0.90 , respectively (23).

\section{Childbirth Attitudes Questionnaire}

Harman created the 15-item CAQ to measure presence or absence as well as the severity of childbirth fear in 
pregnancy (24). Lowe revised the CAQ and added an additional summary question to the scale. The resulting Fear of Childbirth Scale has 16 items with a response scale of 1 to 4 with higher scores indicating higher fear. The validity and internal consistency of the scale were established by Lowe (Cronbach $\alpha=0.83$ ) (25). The Farsi version of this instrument, developed by Khorsandi et al, includes 14 items with total scores ranging from 14 to 56 . It was found to have content validity and good internal consistency (Cronbach $\alpha=0.84$ ) (26). We used the CAQ since fears and generalized anxiety are highly interrelated (27) and the associations of anxiety with fear of childbirth has been demonstrated (28).

Process of Translation

Two English language experts translated the ASP separately. The 2 translated versions were reviewed, and a final draft version was made, which was back-translated into English by an independent and qualified translator. Finally, a bilingual English-Persian translator compared the three versions and proposed a few minor revisions to the final version which were made.

\section{Content Validity}

An expert panel of 10 faculty members consisting of reproductive health specialists, gynecologists, psychologists, midwives, and 2 researchers in instrument development studies evaluated the questionnaire for the necessity of items, and their grammar, wording and scaling. Content validity ratios (CVRs) were calculated using Lawshe's method (29). The necessity of each item was assessed using a 3-point rating scale: (a) not necessary, (b) useful but not essential and (c) essential. None of the calculated CVR values for the items was less than 0.62 , which is the minimum acceptable CVR value for a 10-member panel according to the Lawshe's table.

In the next step, experts judged the clarity, simplicity and relevance of each item on a 4-point Likert scale $(a=$ not relevant, not simple, and not clear to $d=$ very relevant, very simple and very clear). The content validity index (CVI) for every item was calculated by dividing the total number of experts by the number of experts who had chosen the $(c)$ or $(d)$ option for each particular item. We calculated the CVI for relevance, clarity, and simplicity of every item. No item had a CVI less than 0.8 which is recommended by Polit and Beck as the acceptable lower limit for the CVI value (30). A pilot study involving 10 pregnant women with low education was conducted to assess if they felt any difficulty or ambiguity in responding to the items. Most of the women indicated that the Farsi version of the ASP was easy to read and understand.

\section{Statistical Analysis}

Data analyses were performed by SPSS version 18.0 (SPSS, Inc., Chicago, IL) and LISREL version 8.80 (Scientific Software International, Inc., Lincolnwood, IL). The
Shapiro-Wilk test was used to assess the normality of the data. The ASP total score and the scores for its individual items were normally distributed while the CAQ and the STAI total scores were not. Student's $t$ test was used to compare means between groups. The Spearman test was used to evaluate the correlation between the Farsi ASP, the CAQ, and the STAI. Cronbach acoefficient was used to test the reliability of the Farsi version of the ASP. Cronbach avalues above 0.7 were considered as acceptable. To assess the contribution of individual items in each subscale, Cronbach a coefficients were calculated by excluding one item at a time.

A CFA of the factor structure identified by the developer of the ASP was conducted on 14 items of the scale to assess how well it fitted the observed data. A factor loading was considered significant at the 0.05 level if the $t$-value exceeded 1.96. The model fit in the present study was considered acceptable if at least 2 of the following 3 criteria were met: a root mean square error of approximation (RMSEA) values $<0.08, P>0.05$, and relative chi-square $\left(\chi^{2} / d f\right)<3(31,32)$. In addition, the following goodnessof-fit indices were also used to assess the model fit: nonnormed fit index (NNFI $>0.90$ acceptable), the comparative fit index (CFI $>0.90$ acceptable), incremental fit index (IFI $>0.90$ acceptable), goodness of fit index (GFI $>0.90$ acceptable) $(33,34)$, and standardized root mean square residual (SRMR <0.08 acceptable) (35).

Concurrent validity was examined by calculating Spearman correlation coefficients between the ASP and STAI. For discriminant validity, we compared the ASP mean scores of women with low and high levels of childbirth fear. The median CAQ score of 37 was used as a cutoff point for childbirth fear in this study. Predictive validity was examined by comparing the mean score of the ASP in women who preferred cesarean with women who preffered vaginal delivery.

\section{Results}

Subjects

The mean marriage duration and mean gestational age were $5.9 \pm 4.0$ years and $34.6 \pm 3.2$ weeks, respectively (Table 1). Almost half the women (58\%) were primigravida, $\% 17$ had a history of pregnancy loss, and a minority of pregnancies $(9.9 \%)$ were unwanted. The majority of women $(83.5 \%)$ were homemakers, $61.5 \%$ had a high school diploma or less, and $73.8 \%$ had a low monthly family income. There was no significant difference in ASP mean scores of Farsi version between different categories of socio-demographic variables (Table 1). Table 2 presents the means of the instrument items.

Validity

Confirmatory Factor Analysis

A CFA of the 5-factor structure of the ASP yielded unsatisfactory model fit statistics (RMSEA $=0.087$ (CI $\quad[0.077,0.098]), \quad \mathrm{SRMR}=0.092, \quad$ chi-square/ 
Table 1. Participants' Characteristics and Mean Scores for the Farsi Anxiety Scale for Pregnancy

\begin{tabular}{|c|c|c|c|c|}
\hline & No. (\%) & Mean \pm SD & $t$ & $P$ \\
\hline Age (y) & - & $26.3 \pm 5.0$ & - & - \\
\hline \multicolumn{5}{|l|}{ Pregnancy desirability } \\
\hline Wanted & $282(71)$ & $28.6 \pm 5.4$ & & \\
\hline Unwanted or unplanned & $118(29)$ & $27.4 \pm 5.5$ & 1.530 & 0.127 \\
\hline \multicolumn{5}{|l|}{ Income (million rials) } \\
\hline$<10$ & $300(75)$ & $28.1 \pm 5.6$ & & \\
\hline$\geq 10$ & $100(25)$ & $27.3 \pm 5.2$ & 1.273 & 0.204 \\
\hline \multicolumn{5}{|l|}{ Parity } \\
\hline Primiparas & $232(58)$ & $27.9 \pm 5.4$ & & \\
\hline Multiparas & $168(42)$ & $27.8 \pm 5.6$ & .098 & 0.922 \\
\hline \multicolumn{5}{|l|}{ History of pregnancy loss } \\
\hline Yes & $68(17)$ & $28.1 \pm 5.5$ & & \\
\hline No & $332(83)$ & $27.0 \pm 5.5$ & 1.5 & 0.133 \\
\hline \multicolumn{5}{|l|}{ Educational level (y) } \\
\hline$\leq 12$ & $248(62)$ & $28.0 \pm 5.3$ & & \\
\hline$>12$ & $152(38)$ & $27.7 \pm 5.8$ & 0.622 & 0.534 \\
\hline \multicolumn{5}{|l|}{ Job } \\
\hline Homemaker & $340(85)$ & $27.9 \pm 5.5$ & & \\
\hline Employed & $60(15)$ & $28.0 \pm 5.4$ & 0.155 & 0.877 \\
\hline \multicolumn{5}{|l|}{ Housing } \\
\hline Tenant & $256(64)$ & $28.0 \pm 5.5$ & & \\
\hline Owner & $144(36)$ & $27.4 \pm 5.4$ & 1.092 & 0.275 \\
\hline \multicolumn{5}{|c|}{ Hospitalization during pregnancy } \\
\hline No & $358(92)$ & $30.1 \pm 5.9$ & & \\
\hline Yes & $32(8)$ & $30.7 \pm 5.2$ & 0.554 & 0.580 \\
\hline Missing & 10 & & & \\
\hline
\end{tabular}

Table 2. Means of the Instrument Items

\begin{tabular}{|c|c|c|}
\hline Items & Mean & SD \\
\hline 1. I feel relaxed about the health of my baby & 2.02 & 0.82 \\
\hline 2. I feel nervous thinking about the pain of childbirth & 2.72 & 1.03 \\
\hline 3. I feel worried that Iwon't get my figure back after my baby is born & 2.15 & 1.10 \\
\hline 4. I feel secure that the people I know, care about me and will help me & 1.45 & 0.78 \\
\hline 5. I feel concerned about losing control during labor & 2.57 & 1.01 \\
\hline 6. I feel nervous that my baby will have a deformity or a disease & 3.29 & 1.00 \\
\hline 7. I feel confident that the doctors and midwives will take good care of me & 2.42 & 0.87 \\
\hline 8. I feel secure knowing that my husband finds me sexually attractive & 1.71 & 0.86 \\
\hline 9. I feel worried that Idon't have enough support people living near me & 2.24 & 1.11 \\
\hline 10. I feel satisfied with my husband's involvement in my pregnancy & 1.57 & 0.85 \\
\hline 11. I feel secure knowing my husband support me & 1.27 & 0.60 \\
\hline 12. I feel confident that my baby will be born healthy & 1.63 & 0.77 \\
\hline 13. I feel uncertain about the physical changes occurringinmy body & 2.38 & 0.84 \\
\hline 14. I feel scared about feeling helpless during labor & 2.74 & 1.05 \\
\hline
\end{tabular}

$d f=4.03, P<0.05, \mathrm{CFI}=0.87, \mathrm{GFI}=0.91, \mathrm{IFI}=0.87$, and $\mathrm{NNFI}=0.82$ ) (Figure 1). Examination of factor loadings and their $\mathrm{t}$-values revealed that item 9 was not correlated with its intended factor (Figure 1). CFA after removing item 9 confirmed the five-factor structure of the resulting 13-item scale (RMSEA $=0.066$ (CI $[0.053,0.078]$ ), SRMR $=0.069$, chi-square $/ d f=2.71, P<0.05, \mathrm{CFI}=0.93$, $\mathrm{GFI}=0.95, \mathrm{IFI}=0.93$ and $\mathrm{NNFI}=0.90)$ (Figure 2$)$.

\section{Reliability}

We calculated Cronbach a coefficients and descriptive statistics for the ASP subscales originally proposed by the developer (Table 3). Removing one item at a time in each subscale resulted in a slight reduction of the Cronbach $a$ value for the subscale $(<0.1)$, with the exception of item 9 in the support subscale, whose removal increased the Cronbach $a$ value (0.11). Of 5 factors in the structure, 1 


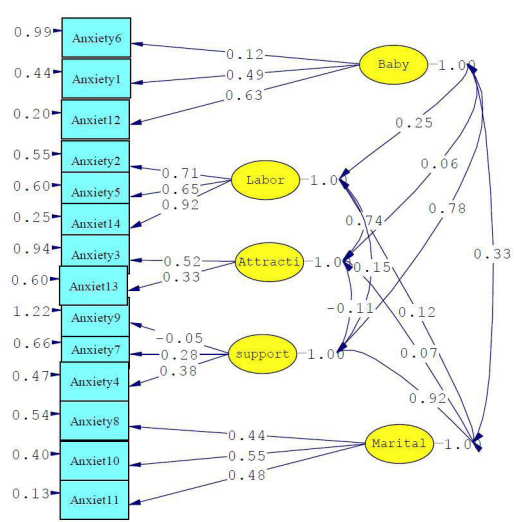

Chi-Square $=272.88, \mathrm{df}=67, \mathrm{P}$-value $=0.00000, \mathrm{RMSEA}=0.087$

Figure 1. Results of Confirmatory Factor Analysis on the 14-item Version.

includes only positively worded items, 2 include only negatively worded items, and 2 are in a mixed item format (with both negatively and positively worded items). The marital factor containing only positively worded items, and the labor factor containing only negatively worded items, had higher Cronbach a values than the factor labeled baby, which has a mixed item format. The support and attractive factors, each containing 2 items, had Cronbach $a$ values of approximately 0.3 .

\section{Concurrent Validity}

The Spearman correlation coefficients between the ASP scores and State-STAI, Trait-STAI, and CAQ scores were $0.61,0.59$, and 0.57 , respectively, indicating moderate relationships $(P<0.001$; Table 4$)$.

\section{Discriminant Validity}

For discriminant validity, we compared the ASP mean scores of women with low and high childbirth fear. Results indicated that women with higher childbirth fear (CAQ score 237$)$ had a higher ASP mean score than women with lower childbirth fear (CAQ score $<37)(P<0.001)$ (Table 5).

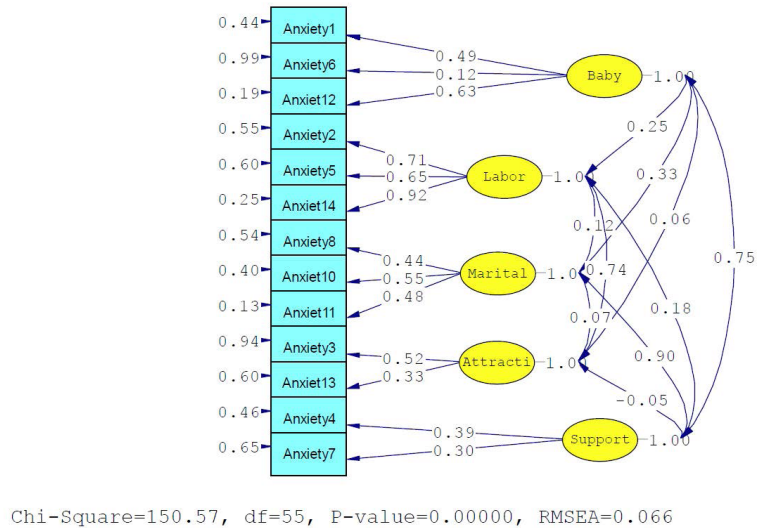

Figure 2. Results of Confirmatory Factor Analysis on the 13-item Version.

\section{Predictive Validity}

The results presented in Table 5 (rows 3 and 4) indicate that there were significant differences in the mean scores of Farsi ASP between women who preferred cesarean and those who preferred normal delivery $(P<0.001$; Table 5$)$.

\section{Discussion}

In the present study, we sought to translate and validate the Farsi version of the ASP which we consider as a useful tool for measuring different aspects of pregnancy related anxiety. In the validation process, one of the items in the 14-item English version of the ASP was omitted. Judged on the satisfactory CVRs and CVIs of all its items, the Farsi ASP is a culturally suitable instrument for use in Iran. All the participants answered all of the items, which is an indication that the instrument is clear and comprehensible. Our findings indicated that the Farsi version of the ASP is a valid instrument for measuring pregnancy-related anxiety in Iranian pregnant women.

The CFA results for the 14-item ASP were not acceptable in our sample. The t-value of item 9 was low, indicating low factor loading. After removing item 9, a rerun of the CFA on the remaining 13 items yielded satisfactory

Table 3. Cronbach's Alpha Coefficients and Means of the Farsi Anxiety Scale for Pregnancy $(n=400)$

\begin{tabular}{lccc}
\hline Factor Wording & Subscales $^{{ }^{a}}$ (Item Number) & Cronbach $\boldsymbol{\alpha}$ & Mean (SD) \\
\hline $\mathrm{M}^{\mathrm{b}}$ & Baby $(1,6,12)$ & 0.47 & $6.9 \pm 1.8$ \\
$\mathrm{~N}^{\mathrm{c}}$ & Labor $(2,5,14)$ & 0.78 & $8.0 \pm 2.6$ \\
$\mathrm{P}^{\mathrm{d}}$ & Marital $(8,10,11)$ & 0.67 & $4.6 \pm 1.8$ \\
$\mathrm{~N}^{\mathrm{c}}$ & Attractive $(3,13)$ & 0.31 & $4.5 \pm 1.5$ \\
$\mathrm{M}^{\mathrm{b}}$ & Support $(4,7,9)$ & 0.18 & $6.1 \pm 1.7$ \\
$\mathrm{P}^{\mathrm{d}}$ & Support $(4,7)$ & 0.29 & $3.9 \pm 1.3$ \\
& Total & $30.2 \pm 5.9$ \\
\hline
\end{tabular}

\footnotetext{
a Subscales as originally assigned by Doyle-Waters.

${ }^{\mathrm{b}} \mathrm{M}$ : mixed item format worded items.

${ }^{\mathrm{c}} \mathrm{N}$ : factor with negatively worded items.

d $\mathrm{P}$ : factor with positively worded items.

e 13 items.
} 
Table 4. Correlation Matrix of the Subscales of the Farsi 13-item ASP, CAQ, and STAI

\begin{tabular}{|c|c|c|c|c|c|c|c|}
\hline & & Baby & Labor & Marital & Attractive & Support & ASP \\
\hline \multirow[t]{5}{*}{ ASP } & Baby & 1 & & & & & \\
\hline & Labor & $.285^{* *}$ & 1 & & & & \\
\hline & Marital & $.182^{* *}$ & $.135^{* *}$ & 1 & & & \\
\hline & Attractive & $.145^{* *}$ & $.370^{* *}$ & .030 & 1 & & \\
\hline & Support & $.296^{* *}$ & $.152^{* *}$ & $.449^{* *}$ & .002 & 1 & \\
\hline CAQ & & $.256^{* *}$ & $.706^{* *}$ & $.353^{* *}$ & $.280^{* *}$ & $.154^{* *}$ & $.550^{* *}$ \\
\hline STAI & State & $.288^{* *}$ & $.570^{* *}$ & $.354^{* *}$ & $.251^{* *}$ & $.290^{* *}$ & $.612^{* *}$ \\
\hline STAI & Trait & $.268^{* *}$ & $.514^{* *}$ & $.353^{* *}$ & $.270^{* *}$ & $.281^{* *}$ & $.584^{* *}$ \\
\hline
\end{tabular}

Abbreviation: ASP, anxiety scale for pregnancy, CAQ, Childbirth attitude questionnaire, STAI, State-Trait Anxiety Index.

$* * P<0.01$.

Table 5. Mean Scores on the Farsi 13-item ASP, Based on Request for Cesarean and CAQ Scores

\begin{tabular}{|c|c|c|c|c|c|}
\hline Scale & & No. (\%) & Anxiety Score & $t$ & $P$ \\
\hline \multirow[t]{2}{*}{ CAQ score } & Low childbirth fear ${ }^{a}$ & $179(46)$ & $25.4 \pm 5.3$ & & \\
\hline & High childbirth fear & $218(54)$ & $30.0 \pm 4.7$ & 9.1 & $<0.001$ \\
\hline \multirow[t]{2}{*}{ Request for cesarean } & Yes & $65(16)$ & $30.5 \pm 5.1$ & & \\
\hline & No & $335(84)$ & $27.4 \pm 5.4$ & 4.2 & $<0.001$ \\
\hline
\end{tabular}

Abbreviation: ASP, anxiety scale for pregnancy, CAQ, Childbirth attitude questionnaire.

a $<37$ vs. $\geq 37$.

results, indicating an acceptable fit to the data. The only exception was the significant result for the chi-square test of the model fit $(P<0.05)$. Although a significant chi-square value is an indication of poor model fit, it may be misleading in large sample sizes (exceeding 200 participants). We used the relative chi-square test (chisquare divided by degrees of freedom $[d f]$ ) which is commonly used to minimize the influence of the sample size $(31,32)$. The relative chi-square value for the Farsi ASP was lower than 3, indicating acceptable goodness-offit. All other GFIs were also in the acceptable range.

The internal consistency of the 13-item Farsi ASP was satisfactory (Cronbach $\alpha=0.70$ ). The Cronbach $a$ coefficients for the 4 subscales of the ASP as originally assigned by Doyle-Waters were lower than acceptable threshold of 0.70 . One explanation may be that the alpha coefficient decreases when the number of items in a scale decreases (36). The alpha values for attractive and support factors, both containing 2 items, were about 0.3 . The lower values of alpha for these factors may also be related to cultural and institutional issues. In the case of the attractive factor the lower alpha might be due to the fact that Iranian women do not care about their appearance in pregnancy, and in the case of the support factor, the reason may be that pregnant women rely more on the support they receive from doctors and midwives rather than their families. Women were aware that their husbands and close family members could not be present during labor and delivery due to hospital rules. The lower value of alpha for baby factor may be due to the fact that it consists of both negatively and positively worded items. This result is consistent with recent evidences $(37,38)$ against the previously recommended method of using the mixed item format (i.e. including both positively and negatively worded items) in scales (39). Using reversed worded items in a mixed format scale may also compromise the construct validity of a scale in cross-cultural research $(40,41)$.

With regard to discriminant validity, the performance of Farsi ASP was satisfactory. It showed a higher level of anxiety in women with high fear of childbirth compared to those with a low level of childbirth fear. Concurrent validity was confirmed by the moderate correlation between the Farsi ASP and STAI scores. In Doyle-Waters study, the correlations between the scores of the state and trait subscales of ASP and the STAI were 0.57 and 0.61 , respectively. The correlations between the ASP subscale scores and STAI subscale scores were in the range 0.33 to $0.45(20)$.

The level of pregnancy anxiety as measured by the Farsi ASP was higher in women who preferred cesarean compared to those who did not. This result supports the predictive validity of the instrument and is consistent with the findings of previous studies $(7,25)$. Women who preferred cesarean had a higher level of anxiety about labor and the support that they would receive than those who preferred normal delivery.

Our results showed that the mean scores of the Farsi ASP were not significantly different between categories of socio-demographic variables, indicating that all women regardless of age, parity, household income level, and employment status had pregnancy-related anxiety. This is in line with the findings of a study by Carmona Monge et al on the validation of the Spanish version of the Cambridge 
Worry Scale which did not find any significant differences in levels of worry between different categories of sociodemographic variables such as age, having a history of miscarriage, being employed, or educational level (42).

In this study, we examined the validity and reliability of the ASP in women in the third trimester of pregnancy. Further validation studies are needed to examine the validity and reliability of the scale in women in the first and second trimester of pregnancy.

\section{Conclusion}

The results of the present study showed that the 13item Farsi version of the ASP is a valid instrument for measuring pregnancy-related anxiety in Iranian women. Several GFIs indicated that the 5-factor structure of the scale fitted our data well. Our results also confirmed the reliability of the whole scale, but the tests for the reliability of the individual subscales yielded unsatisfactory results. It is probable that the mixed-item format of the scale was responsible for the low internal consistency results. We recommend that in future studies of ASP, the wording of items be modified so that all items are negatively worded.

\section{Conflict of Interests}

No competing financial interests exist.

\section{Ethical Issues}

The Ethics Committee of the Sabzevar University of Medical Sciences approved the study protocol (ethics code: Medsab.ac. 38, 93). All women consented to participate in the study. The participants were informed that their participation was voluntary and their information would be kept confidential. Permission to use the ASP was obtained from the author before the study was started.

\section{Financial Support}

Sabzevar University of Medical Sciences financed this work.

\section{Acknowledgements}

We thank all pregnant women who participated in this study and the midwives who collected the data. We appreciate our colleagues who took part in the expert panel for the evaluation of the content validity.

\section{References}

1. Van den Bergh BR, Mulder EJ, Mennes M, Glover V. Antenatal maternal anxiety and stress and the neurobehavioural development of the fetus and child: links and possible mechanisms. A review. Neurosci Biobehav Rev. 2005;29(2):237-258. doi:10.1016/j.neubiorev.2004.10.007

2. Bayrampour H, Ali E, McNeil DA, Benzies K, MacQueen G, Tough S. Pregnancy-related anxiety: A concept analysis. Int J Nurs Stud. 2016;55:115-130. doi:10.1016/j. ijnurstu.2015.10.023

3. Guardino CM, Schetter CD. Understanding Pregnancy Anxiety: Concepts, Correlates, and Consequences. Zero to three. 2014;34:12-21.

4. Huizink AC, Mulder EJ, Robles de Medina PG, Visser GH, Buitelaar JK. Is pregnancy anxiety a distinctive syndrome? Early Hum Dev. 2004;79(2):81-91. doi:10.1016/j. earlhumdev.2004.04.014

5. Glynn LM, Schetter CD, Hobel CJ, Sandman CA. Pattern of perceived stress and anxiety in pregnancy predicts preterm birth. Health Psychol. 2008;27(1):43-51. doi:10.1037/02786133.27.1.43

6. Alder J, Fink N, Bitzer J, Hosli I, Holzgreve W. Depression and anxiety during pregnancy: a risk factor for obstetric, fetal and neonatal outcome? A critical review of the literature. J Matern Fetal Neonatal Med. 2007;20(3):189209. doi:10.1080/14767050701209560

7. Martini J, Knappe S, Beesdo-Baum K, Lieb R, Wittchen HU. Anxiety disorders before birth and self-perceived distress during pregnancy: associations with maternal depression and obstetric, neonatal and early childhood outcomes. Early Hum Dev. 2010;86(5):305-310. doi:10.1016/j. earlhumdev.2010.04.004

8. Orr ST, Reiter JP, Blazer DG, James SA. Maternal prenatal pregnancy-related anxiety and spontaneous preterm birth in Baltimore, Maryland. Psychosom Med. 2007;69(6):566570. doi:10.1097/PSY.0b013e3180cac25d

9. Davis EP, Sandman CA. The timing of prenatal exposure to maternal cortisol and psychosocial stress is associated with human infant cognitive development. Child Dev. 2010;81(1):131-148. doi:10.1111/j.1467-8624.2009.01385.x

10. Aksoy M, Aksoy AN, Dostbil A, Celik MG, Ince I. The Relationship between Fear of Childbirth and Women's Knowledge about Painless Childbirth. Obstet Gynecol Int. 2014;2014:274303. doi:10.1155/2014/274303

11. Takegata M, Haruna M, Matsuzaki M, et al. Translation and validation of the Japanese version of the Wijma Delivery Expectancy/Experience Questionnaire version A. Nurs Health Sci. 2013;15(3):326-332. doi:10.1111/nhs.12036

12. Fenaroli V, Saita E. Fear of childbirth: a contribution to the validation of the italian version of the wijma delivery expectancy/experience questionnaire (WDEQ). TPM. 2013;20(2):1-24. doi:10.4473/TPM20.2.3

13. Delaram M, Soltanpour F. The Effect of Counseling in Third Trimester on Anxiety of Nulliparous Women at the Time of Admission for Labor. Zahedan Journal of Research in Medical Sciences. 2012;14(2):61-65.

14. Brunton RJ, Dryer R, Saliba A, Kohlhoff J. Pregnancy anxiety: A systematic review of current scales. J Affect Disord. 2015;176:24-34. doi:10.1016/j.jad.2015.01.039

15. Blair MM, Glynn LM, Sandman CA, Davis EP. Prenatal maternal anxiety and early childhood temperament. Stress. 2011;14(6):644-651. doi:10.3109/10253890.2011.594121

16. Kramer MS, Lydon J, Seguin L, et al. Stress pathways to spontaneous preterm birth: the role of stressors, psychological distress, and stress hormones. Am J Epidemiol. 2009;169(11):1319-1326. doi:10.1093/aje/ kwp061

17. Reck C, Zimmer K, Dubber S, Zipser B, Schlehe B, Gawlik $\mathrm{S}$. The influence of general anxiety and childbirth-specific anxiety on birth outcome. Arch Womens Ment Health. 2013;16(5):363-369. doi:10.1007/s00737-013-0344-0

18. Levin JS. The factor structure of the pregnancy anxiety scale. J Health Soc Behav. 1991;32(4):368-381.

19. Meades R, Ayers S. Anxiety measures validated in perinatal populations: a systematic review. J Affect Disord. 
2011;133(1-2):1-15. doi:10.1016/j.jad.2010.10.009

20. Doyle-Waters MM, Kishor N, Doyle-Baker PK. Development and validation of an anxiety scale for pregnancy. Med Sci Sports Exerc. 2001;33(5 Supplement): S168.

21. Spielberger C, Gorsuch R, Lushene R, Vagg P, Jacobs G. Manual for the State-Trait Anxiety Inventory. Palo Alto, CA: Consulting Psychologists Press; 1983.

22. Barnes LLB, Harp D, Jung WS. Reliability Generalization of Scores on the Spielberger State-Trait Anxiety Inventory. Educ Psychol Meas. 2002;62(4):603-618. doi:10.1177/0013164402062004005

23. Mahram B. Validity of Spielberger state-trait anxiety inventory (STAI) in Mashhad city. Tehran: Allameh Tabatabaei University; 1993.

24. Harman P. Fear of Childbirth and Related Incidence of Complications in Labor and Delivery. The 33rd Annual Meeting of the American College Nurse-Midwives; 1988; Detroit, MI.

25. Lowe NK. Self-efficacy for labor and childbirth fears in nulliparous pregnant women. J Psychosom Obstet Gynaecol. 2000;21(4):219-224. doi:10.3109/01674820009085591

26. Khorsandi M, Ghofranipour F, Heydarnia A, et al. The effect of childbirth preparation classes on childbirth fear and normal delivery among primiparous women. Arak Medical University Journal. 2008;11(3):29-36.

27. Suinn RM. The relationship between fears and anxiety: A further study. Behav Res Ther. 1969;7(3):317-318. doi:10.1016/0005-7967(69)90013-8

28. Storksen HT, Eberhard-Gran M, Garthus-Niegel S, Eskild A. Fear of childbirth; the relation to anxiety and depression. Acta Obstet Gynecol Scand. 2012;91(2):237242. doi:10.1111/j.1600-0412.2011.01323.x

29. Lawshe $\mathrm{CH}$. A quantitative approach to content validity. Pers Psychol. 1975;28(4):563-575. doi:10.1111/j.1744-6570.1975. tb01393.x

30. Polit D, Beck C. Nursing Research: Principles and Methods. 46th ed. Philadelphia: Lippincott; 2004.

31. Kline RB. Principles and Practice of Structural Equation
Modeling. 2ed ed. New York: The Guilford Press; 2005.

32. Tabachnick BG, Fidell LS. Using Multivariate Statistics. Boston: Allyn and Bacon; 2001.

33. Hu LT, Bentler PM. Evaluating Model Fit. CA: Thousand Oaks: Sage; 1995.

34. Bentler PM, Bonett DG. Significance tests and goodness of fit in the analysis of covariance structures. Psychol Bull. 1980;88(3):588-606. doi:10.1037/0033-2909.88.3.588

35. Hu Lt, Bentler PM. Cutoff criteria for fit indexes in covariance structure analysis: Conventional criteria versus new alternatives. Struct Equ Modeling: A Multidisciplinary Journal. 1999;6(1):1-55. doi:10.1080/10705519909540118

36. Field A. Discovering Statistics Using SPSS. 3rd ed. Sage publications; 2009.

37. van Sonderen E, Sanderman R, Coyne JC. Ineffectiveness of reverse wording of questionnaire items: let's learn from cows in the rain. PLoS One. 2013;8(7):e68967. doi:10.1371/ journal.pone. 0068967

38. Ebesutani C, Drescher CF, Reise SP, et al. The Loneliness Questionnaire-Short Version: an evaluation of reverseworded and non-reverse-worded items via item response theory. J Pers Assess. 2012;94(4):427-437. doi:10.1080/002 23891.2012.662188

39. Rorer LG. The great response-style myth. Psychol Bull. 1965;63(3):129-156. doi. 10.1037/h0021888

40. Wong N, Rindfleisch A, Burroughs JE. Do reverse-worded items confound measures in cross-cultural consumer research? The case of the material values scale. J Consum Res. 2003;30:72-91. doi: 10.1086/374697

41. Wouters E, Booysen Fle R, Ponnet K, Baron Van Loon F. Wording effects and the factor structure of the Hospital Anxiety \& Depression Scale in HIV/AIDS patients on antiretroviral treatment in South Africa. PLoS One. 2012;7(4):e34881. doi:10.1371/journal.pone.0034881

42. Carmona Monge FJ, Penacoba-Puente C, Marin Morales D, Carretero Abellan I. Factor structure, validity and reliability of the Spanish version of the Cambridge Worry Scale. Midwifery. 2012;28(1):112-119. doi:10.1016/j. midw.2010.11.006

Copyright ( 2018 The Author (s); This is an open-access article distributed under the terms of the Creative Commons Attribution License (http://creativecommons.org/licenses/by/4.0), which permits unrestricted use, distribution, and reproduction in any medium, provided the original work is properly cited. 